\title{
LINC00461, a long non-coding RNA, is important for the proliferation and migration of glioma cells
}

\author{
Yali Yang ${ }^{1, *}$, Mingxin Ren ${ }^{1, *}$, Chao Song ${ }^{1}$, Dan Li $^{1}$, Shahid Hussain Soomro ${ }^{1}$, Yajie \\ Xiong ${ }^{1}$, Hongfeng Zhang ${ }^{2}$ and Hui Fu ${ }^{1}$ \\ ${ }^{1}$ Department of Anatomy and Embryology, School of Basic Medical Sciences, Wuhan University, Wuhan 430071, China \\ ${ }^{2}$ Department of Pathology, The Central Hospital of Wuhan, Tongji Medical College, Huazhong University of Science and \\ Technology, Wuhan 430014, China \\ *These authors have contributed equally to this work \\ Correspondence to: Hui Fu, email: hueyfu@hotmail.com \\ Hongfeng Zhang, email: zhf152@163.com
}

Keywords: InCRNAs, LINC00461, glioma, proliferation, migration

Received: February 10, $2017 \quad$ Accepted: July 25, $2017 \quad$ Published: August 18, 2017

Copyright: Yang et al. This is an open-access article distributed under the terms of the Creative Commons Attribution License 3.0 (CC BY 3.0), which permits unrestricted use, distribution, and reproduction in any medium, provided the original author and source are credited.

\section{ABSTRACT}

An increasing number of reports have revealed that long non-coding RNAs are important players in tumorigenesis. Here we showed that long non-coding RNA LINC00461 is highly expressed in glioma tissues compared to non-neoplastic brain tissues. The knockdown of LINC00461 suppressed cyclinD1/A/E expression which led to G0/G1 cell cycle arrest and inhibited cell proliferation in glioma cells. LINC00461 suppression also inhibited glioma cell migration and invasion. The function of LINC00461 in glioma cells is partially mediated by MAPK/ERK and PI3K/AKT signaling pathways as down-regulation of LINC00461 expression suppressed ERK1/2 and AKT activities. Moreover, LINC00461 knockdown decreased expression levels of microRNA miR-9 and flanking genes MEF2C and TMEM161B. Taken together, our results demonstrate that LINC00461 is important for glioma progression affecting cell proliferation, migration and invasion via MAPK/ERK, PI3K/AKT, and possibly other signaling pathways.

\section{INTRODUCTION}

Long non-coding RNAs (lncRNAs) are defined as transcripts of greater than 200 nucleotides without evident protein coding function $[1,2]$. In the whole genome, the protein coding portion constitutes approximately $1.5 \%$ [3], while $70 \%-90 \%$ portion is transcribed to produce a large transcriptome of lncRNAs [4]. LncRNAs are involved in a variety of biological functions such as chromosomal dosage compensation, imprinting, epigenetic regulation, apoptosis, cell cycle control, cell growth and differentiation [5-10]. Therefore, aberrant lncRNA expression can cause human cancers [11], such as breast cancer $[12,13]$, colorectal cancer $[14,15]$, hepato-cellular cancer [15-17], prostate cancer [18, 19], non-small cell lung cancer [20], glioma [21] and others [22].
Gliomas account for the majority of malignant brain tumors in adults, causing approximately $80 \%$ of all malignant brain tumors [23]. According to the Histopathology, the World Health Organization (WHO) has divided gliomas into four grades (I-IV) [24]. Gliomas are rarely curable especially for glioblastoma (grade IV) [25]. Current standard therapy for glioblastomas includes maximal safe surgical resection, followed by concurrent radiation with temozolomide (TMZ), an oral alkylating agent [26]. But the treatment is not effective due to the high proliferation rate and aggressive invasion of glioblastomas. The median survival of patients is merely 15 months [25]. Thus, it is urgent to advance our understanding of regulatory mechanisms involved in the initiation and progression of gliomas for developing novel and effective therapeutic approaches. 
Here, we have reported that lncRNA LINC00461 is up-regulated in human gliomas. LINC00461 is located at an intergenic region of human chromosome 5 between two protein-coding genes $M E F 2 C$ (myocyte enhancer factor 2C) and TMEM161B (transmembrane protein 161B). Our study suggested that LINC00461 is important for glioma cell proliferation, migration and invasion. Furthermore, we found that LINC00461 could potentially activate MAPK/ ERK and PI3K/AKT pathways and expression levels of genes in its vicinity as well.

\section{RESULTS}

\section{LINC00461 is expressed in neural stem/glioma cells}

Previously, we compared transcriptomes of mouse spinal cords at E13.5 (embryonic day 13.5) with those at P0 (postnatal day 0) and identified several genes that are highly expressed at E13.5, including lncRNA C130071C03Rik. Now further studies revealed that it is specifically expressed in the ventricular zone of the mouse spinal cord at E11.5 (Figure 1A) and E13.5 (Figure 1B), where neural stem/precursor cells are located. At P0, its expression spreads out to the whole spinal cord (Figure 1C). In the mouse brain, we detected its expression in the subventricular zone (SVZ) at P0 (Supplementary Figure 1A, 1B). Real-time PCR analysis showed that C130071C03Rik is highly expressed in mouse neural tissues compared to non-neural tissues (Figure 1D).

The liftOver program was used to identify single mapped orthologous regions in genomes of diverse species. We found that the ortholog of 1 ncRNA C130071C03Rik in humans was LINC00461. LINC00461 is transcribed from an intergenic region of human chromosome 5 between MEF2C and TMEM161B (Figure 2A). Using in situ hybridization (ISH) technique, we demonstrated that LINC00461 transcript predominantly locates in the cytoplasm of U251 and U87MG glioma cells (Supplementary Figure 1C).

It has been reported that glioblastoma cells harbor some properties similar to those of neural stem cells. Their gene expression profiles resemble each other. Therefore we decided to find out whether this lncRNA is enriched in gliomas. Glioma datasets GSE16011 and GSE4290 showed that expression levels of LINC00461 were upregulated in gliomas (grade I-IV in GSE16011, grade II-IV in GSE4290) compared to the control (Figure 2B). We also checked the expression of SOX2, a neural stem cell marker, and found that SOX2 mRNA expression levels were also up-regulated in gliomas (Figure 2C). In our own Chinese glioma collection, we found that expression levels of both LINC00461 and SOX2 mRNAs were markedly higher in gliomas than those in nonneoplastic brain tissues $(P<0.001)$ (Figure 2D). Pearson correlation analysis revealed significant and positive correlation between LINC00461 and SOX2 mRNAs in GSE16011 and GSE4290 datasets (Figure 2E). Again, a positive correlation between mRNA levels of LINC00461 and SOX2 was detected in Chinese glioma samples (Figure 2E). Up-regulation of SOX2 has been linked to the development and maintenance of gliomas. Our findings suggested that LINC00461 might be involved in the development of gliomas, regulating stem-cell like properties in gliomas.

\section{The knockdown of LINC00461 decreased cell viability of glioma cells, while had no effects on cell apoptosis}

Lentivirus-mediated short hairpin RNAs (shRNAs) were applied to knockdown LINC00461 expression. 48 hours after lentivirus infection, expression levels of LINC00461 were measured by real-time PCR to determine the effect of LINC00461 shRNA. We had designed two different shRNAs. Both significantly suppressed expression levels of LINC00461 in U251 and U87MG cells (Figure 3A, Supplementary Figure 3A) and reduced the cell viability at 2, 3, 4 and 5 days post the lentivirus treatment (Figure 3B, Supplementary Figure 3B).

Then we decided to find out whether LINC00461 knockdown induces cell apoptosis. For this purpose, Annexin V-PE/7-AAD assays were performed to measure numbers of cells that were viable (Annexin v-, 7-AAD-), underwent early apoptosis (Annexin $\mathrm{v}^{+}, 7$-AAD-), late apoptosis (Annexin $\mathrm{v}+, 7-\mathrm{AAD}+$ ), or necrosis (Annexin $\mathrm{V}-, 7-\mathrm{AAD}+$ ) (Figure 3C). Apoptosis rates (early plus late apoptosis) after LINC00461 shRNA treatment were $6.18 \pm 1.30 \%$ in U251 cells and $7.01 \pm 1.07 \%$ in U87MG cells, similar to those in control groups $(5.1 \pm 0.56 \%$ in U251 cells and $5.61 \pm 0.42 \%$ in U87MG cells) (Figure 3D). Statistical analysis showed no significant difference between treatment and control groups $(P=0.2396$ in U251 cells and $P=0.0662$ in U87MG cells) (Figure 3D). We also measured expression levels of apoptotic protein caspase- 3 after the shRNA treatment. Results showed that protein levels of caspase- 3 and cleaved caspase- 3 were not affected by LINC00461 shRNA (Supplementary Figure 2). These results indicated that knockdown of LINC00461 has little effect on apoptosis.

\section{LINC00461 knockdown led to G0/G1 phase arrest and inhibited cell proliferation}

To evaluate the effect of LINC00461 on cell proliferation, we used both ki67 antibody and EdU staining to measure the proliferation rate. Ki67 antibody can recognize a protein that is present during all active phases of the cell cycle, but absent in the resting stage. EdU is an analog for thymidine and can be incorporated into the newly synthesized DNA at S phase of the cell cycle. The percentage of Ki67 positive cells after 
LINC00461 shRNA treatment was $59.50 \pm 0.33 \%$ in U251 cells and $45.20 \pm 0.23 \%$ in U87MG cells, while in control groups it was $79.18 \pm 0.40 \%$ in U251 cells $(P<0.01)$ and $69.95 \pm 0.26 \%$ in U87MG cells $(P<$ 0.001 ) (Figure 4A, 4B). Results were confirmed by EdU staining experiments. In LINC00461 knockdown groups, the percentage of EdU positive cells was 40.98 $\pm 1.68 \%$ in U251 cells and $23.23 \% \pm 1.64 \%$ in $\mathrm{U} 87 \mathrm{MG}$ cells, compared to $56.91 \pm 2.79 \%(P<0.05)$ in $\mathrm{U} 251$ cells and $38.15 \pm 2.24 \%(P<0.001)$ in U87MG cells for control groups (Figure 4C, 4D). Our results suggested that suppressed expression of LINC00461 inhibits cell proliferation which contributes to the reduction of cell viability.

In order to explore mechanisms underlying the anti-proliferation effect of LINC00461 knockdown on glioma cells, we analyzed cell cycle distribution by flow cytometry. As showed in Figure 5, 48 hours after downregulation of LINC00461, the fraction of cells in G0/G1 phase increased to $77.86 \pm 1.59 \%$ in U251 cells compared to $59.31 \pm 1.07 \%$ in control cells (Figure 5A, 5B). Similar results were obtained with U87MG cells. The fraction of cells in G0/G1 phase increased to $70.14 \pm 1.13 \%$ in experimental groups, whereas the fraction in control group was $55.65 \pm 0.95 \%$ (Figure $5 \mathrm{~A}, 5 \mathrm{~B}$ ). The fraction of cells in $\mathrm{S}$ phase decreased significantly after LINC00461 shRNA treatment (treatment group 17.08\% $\pm 1.55 \%$ vs. control group $30.57 \pm 0.56 \%$ in U251 cells, $19.57 \pm 1.52 \%$ vs. $28.79 \pm 2.06 \%$ in U87MG cells) (Figure $5 \mathrm{~A}, 5 \mathrm{~B}$ ).

We further measured expression levels of some proteins important for regulating the cell cycle. In LINC00461 knockdown groups, expression levels of cyclinD1, CDK4, cyclin A, cyclin E mRNAs significantly decreased in U251 and U87MG cells (Figure 5C). Moreover, expression levels of cyclinD1 protein decreased about 50\% in U251 cells $(P<0.01)$ and $65 \%$ in U87MG cells $(P<0.001)$ (Figure 5D). These results showed that down-regulation of LINC00461 can reduce expression
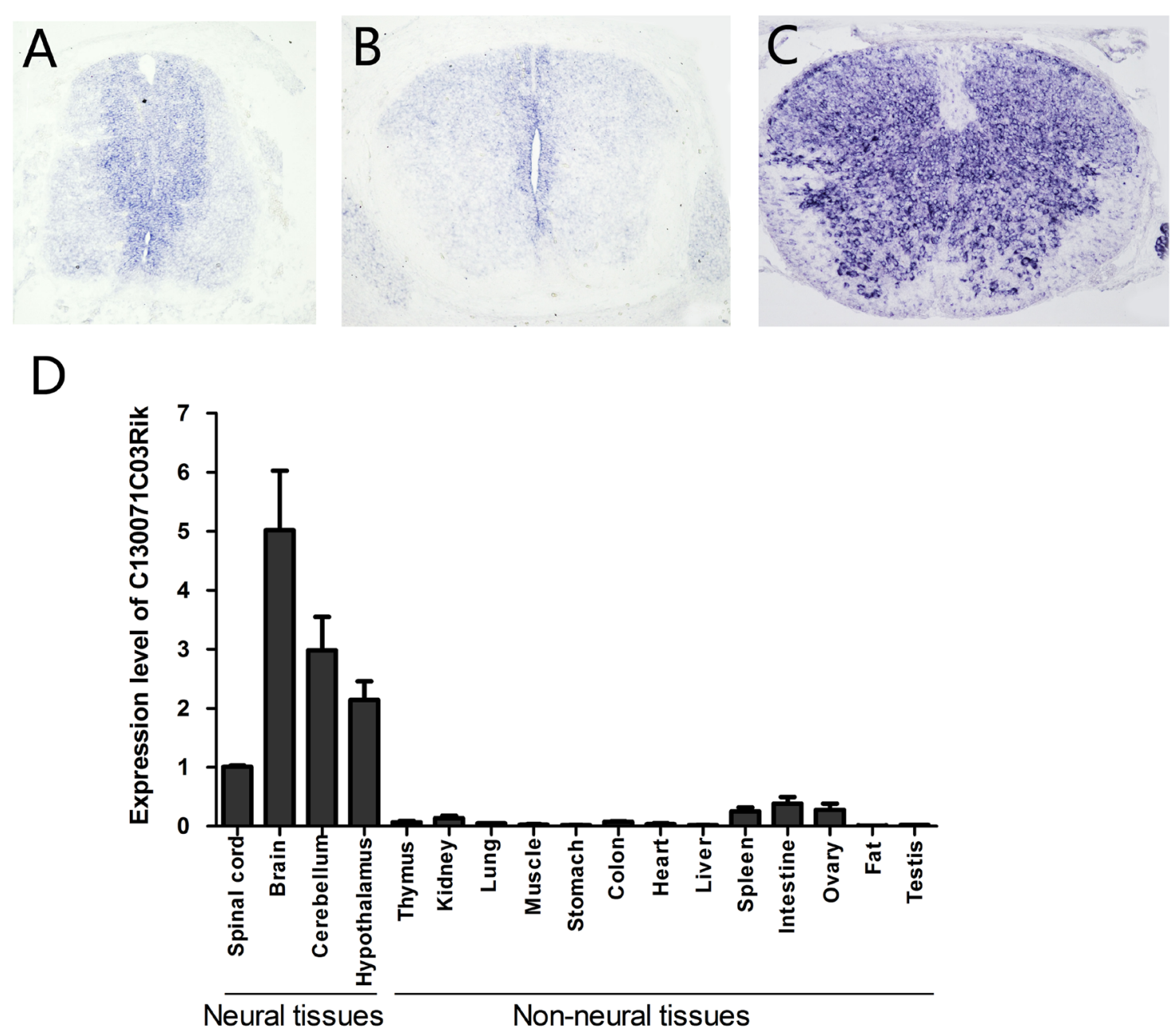

Figure 1: Mouse IncRNA C130071C03Rik is specifically expressed in neural stem cells during development and highly enriched in neural tissues in adults. The expression of C130071C03Rik was detected in mouse spinal cord at E11.5 (A), E13.5 (B), and P0 (C) by in situ hybridization. (D) Relative expression levels of C130071C03Rik in different mouse tissues/organs were measured by real-time PCR at P60. The average expression level of C130071C03Rik in the spinal cord was set as 1. Data are presented as mean $\pm \mathrm{SEM}$. 
levels of cyclinD1, CDK4, cyclin A and cyclin E, which leads to G0/G1 phase arrest and the delay of cell cycle progression.

\section{LINC00461 knockdown inhibited cell migration and invasion}

We tried to find out whether down-regulation of LINC00461 could affect cell migration and invasion, which are key determinants for tumor aggressiveness and metastasis. Wound-healing assay was performed to investigate the effect of LINC00461 on cell migration. At the time points of $12 \mathrm{~h}$ and $24 \mathrm{~h}$ after wound scraping, slow migration in LINC00461 knockdown group was observed in both U251 and U87MG cells (Figure 6A, 6B, Supplementary Figure 3C). Transwell assay was also used to further verify the effect of LINC00461 on migratory and invasive properties of tumor cells. After LINC00461

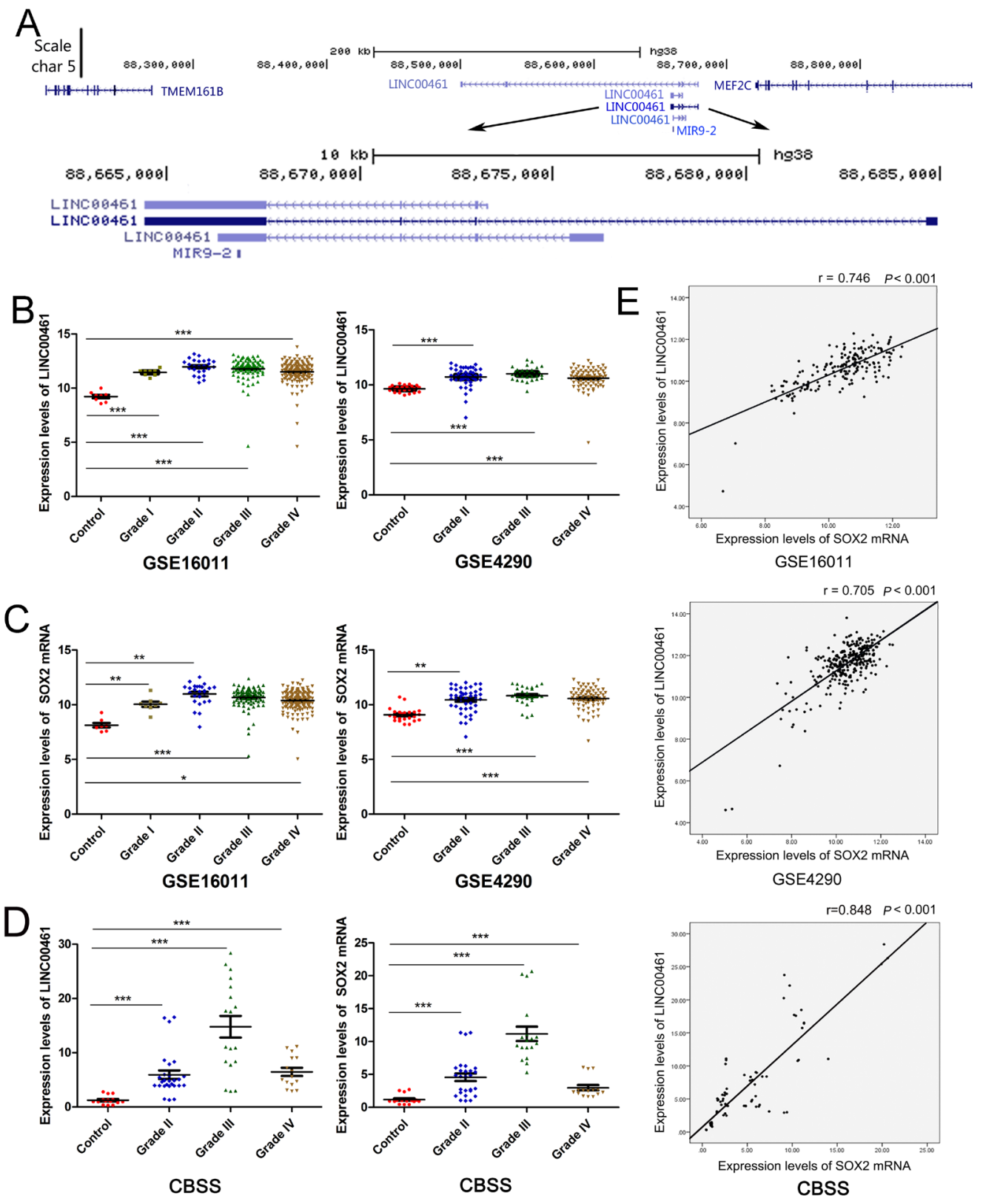

Figure 2: Expression levels of LINC00461 are up-regulated in glioma tissues and positively correlated with those of SOX2. (A) UCSC genome browser view of the LINC00461 locus in the human genome. (B) Expression levels of LINC00461 were analyzed in GSE16011 and GSE4290 glioma datasets. (C) Expression levels of SOX2 mRNA were analyzed in GSE16011 and GSE4290 glioma datasets. (D) Expression levels of LINC00461 and SOX2 in 5 nonneoplastic brain tissues and 19 glioma tissues were measured by real-time PCR in Chinese brain sample set (CBSS). (E) The expression of LINC00461 positively correlated with that of SOX2 in GSE16011, GSE4290, and CBSS. Each sample has been measured three times. Data are presented as mean \pm SEM. ${ }^{*}, P<0.05 ;{ }^{* *}, P<0.01$; ${ }^{* * *}, P<0.001$. 
shRNA treatment, numbers of cells underwent migration and invasion were markedly reduced in U251 $(P<0.01$ in migration assay and $P<0.05$ in invasion assay) and U87MG cells $(P<0.01$ in migration assay and $P<0.05$ in invasion assay) (Figure 6C, 6D). These data showed that knockdown of LINC00461 reduces migratory and invasive properties of glioma cells.

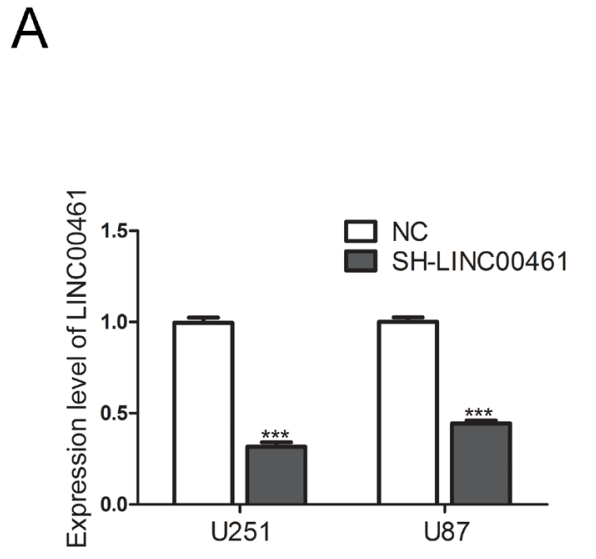

\section{LINC00461 knockdown suppressed expression levels of markers for stem cells and EMT}

Our data have showed that LINC00461 is highly expressed in neural stem cells and increases cell proliferation and migration, which are important features of stem cells. We decided to find out whether LINC00461 regulates "stemness" of glioma cells. We chose some

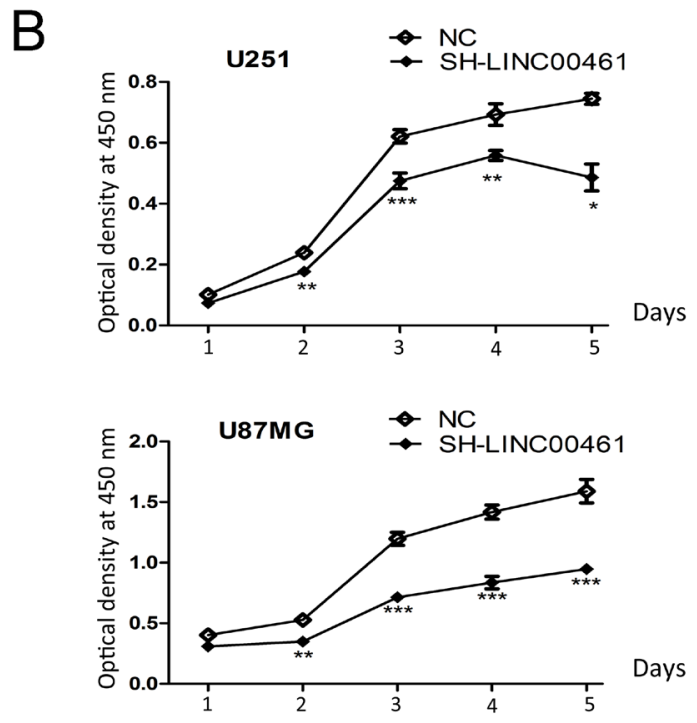

C
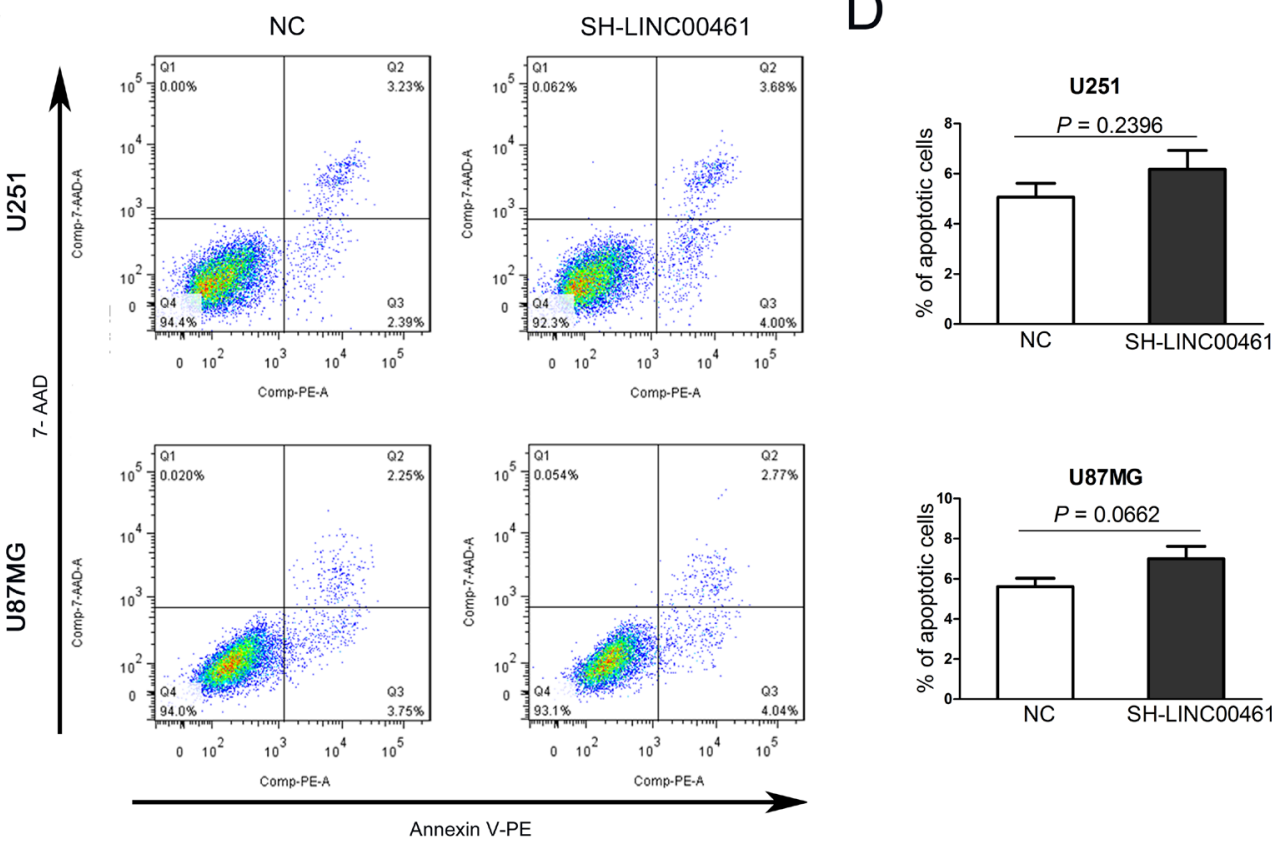

Figure 3: The knockdown of LINC00461 decreased cell viability with no effects on cell apoptosis. (A) The efficiency of LINC00461 knockdown in both U251 and U87MG cells was measured by real-time PCR. (B) The cell viability was measured by CCK8 assay. The optical density at $450 \mathrm{~nm}$ was used as the positive index of cell viability. (C) The cell apoptosis was analyzed by Annexin V-PE/7-AAD assay. (D) Histograms showing total apoptotic rates (containing early and late apoptosis rates) in U251 and U87MG cells. Cells treated with scrambled sequences were used as the negative control. SH-LINC00461: shRNA\#1 against LINC00461; NC: negative control. Data are presented as mean \pm SEM. ${ }^{*}, P<0.05 ;^{* *}, P<0.01 ;{ }^{* * *}, P<0.001$. 
classic stem cell markers, such as SOX2, Nestin and CD44. The result showed that LINC00461 knockdown significantly reduced mRNA levels of stem cell markers: SOX2 and CD44 in U251 cells, Nestin and CD44 in U87MG cells (Figure 7C).

It is well known that cancer cells usually undergo EMT to gain migratory and invasive properties. So we analyzed expression levels of EMT markers as well. Realtime PCR results showed that LINC00461 knockdown suppressed mRNA levels of EMT markers, such as
N-cadherin and ZEB1 (Figure 7B), in U251 and U87MG cells.

\section{Potential mechanisms for LINC00461 promoting glioma cell proliferation, migration and invasion}

MAPK/ERK pathway is well known for its roles in oncogenesis. Phosphatidylinositol 3-kinase (PI3K)/ AKT signaling pathway also plays a major role in cell proliferation, migration and invasion, especially in glioma

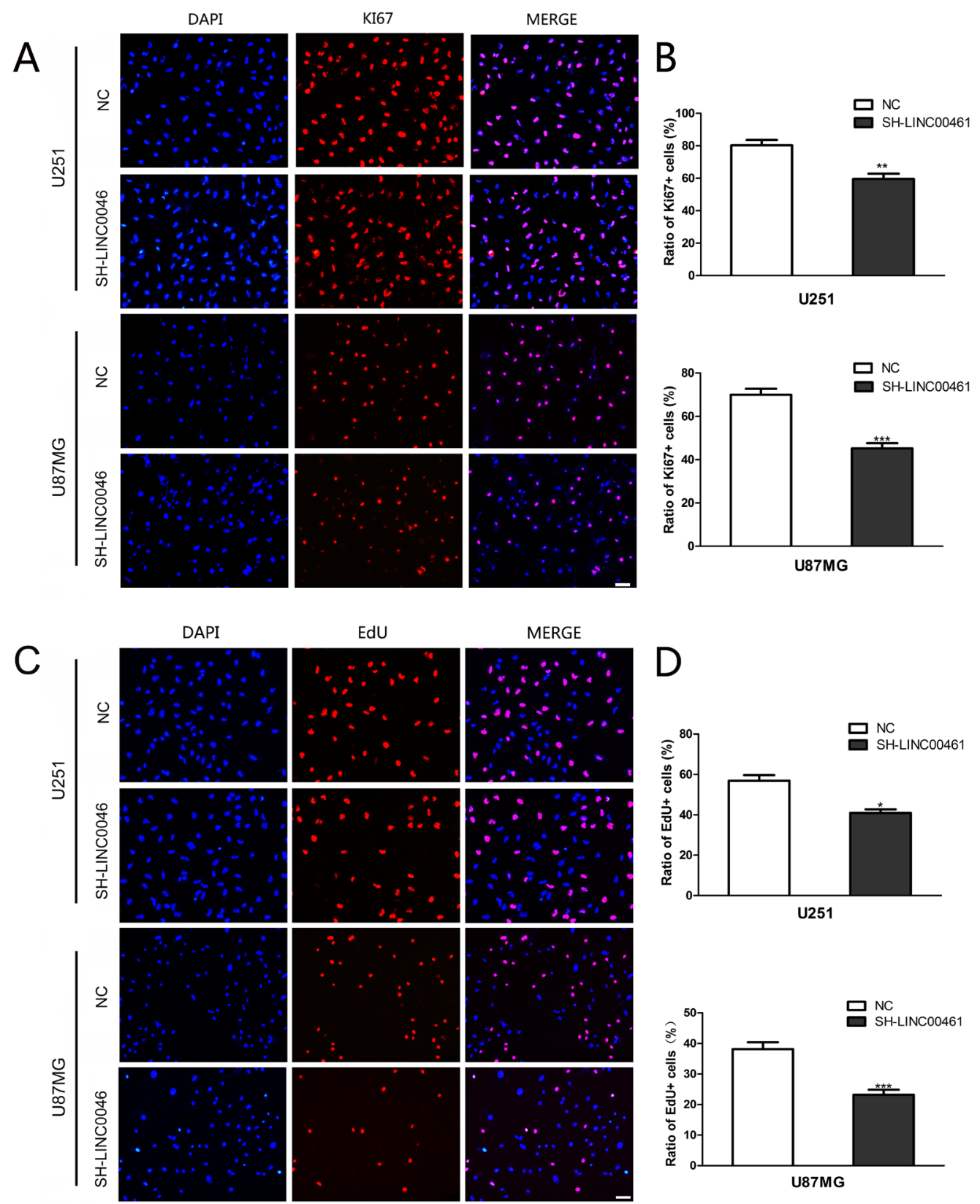

Figure 4: LINC00461 knockdown inhibited cell proliferation. (A) Images of U251 and U87MG cells stained with the antibody against ki67. (B) Histograms showing ratios of proliferating ki67 positive cells. (C) Cell proliferation was measured by EdU assay in U251 and U87MG cells. (D) Histograms showing ratios of EdU positive cells. Data are presented as mean \pm SEM. ${ }^{*}, P<0.05 ;{ }^{* *}, P<0.01 ;{ }^{* * *}$, $P<0.001$. Scale bar: $50 \mu \mathrm{m}$. 
cells. In order to find out the mechanism underlying the regulation of LINC00461 on glioma cells, we studied effects of LINC00461 on different signaling pathways. Expression levels of total and phosphorylated AKT and ERK1/2 proteins were measured in glioma cells by Western blot technique. Results showed that LINC00461 knockdown significantly suppressed phosphorylation of ERK1/2 proteins $(P<0.001)$ in both $\mathrm{U} 251$ and U87MG cells (Figure 7A, 7B). Moreover, down-regulation of LINC00461 also decreased expression levels of total AKT $(P<0.01)$ and phosphorylated AKT proteins $(P<0.001)$ in both U251 and U87MG cells (Figure 7A, 7B). These
A

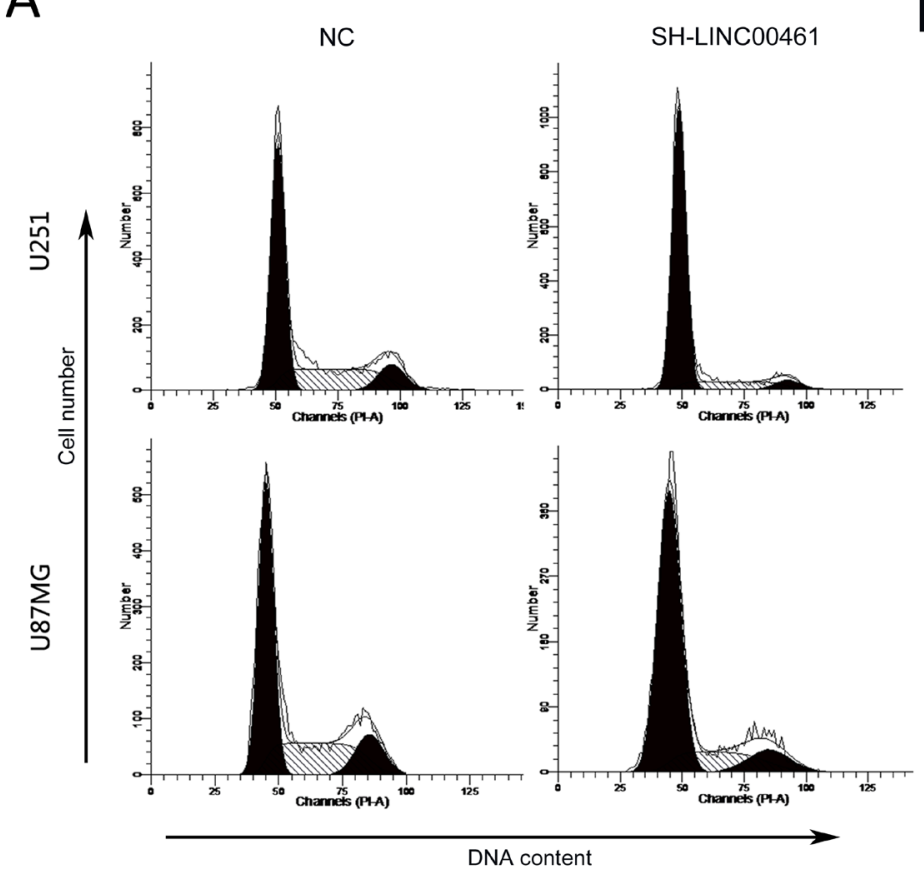

B
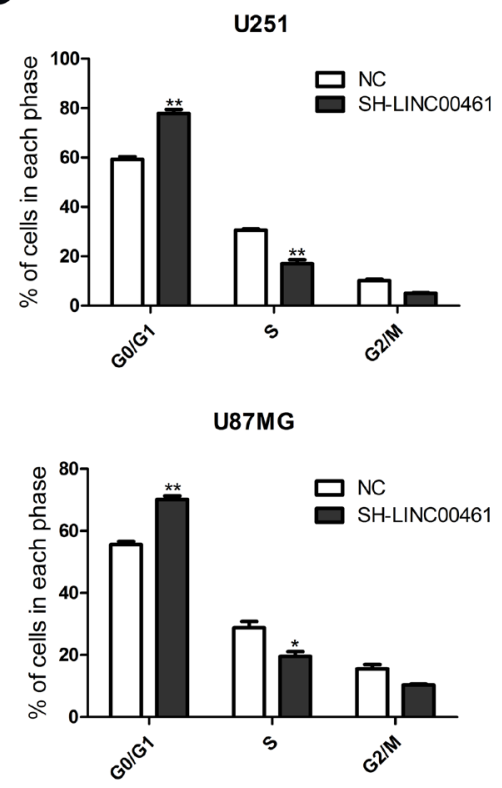

C

U251

U87MG
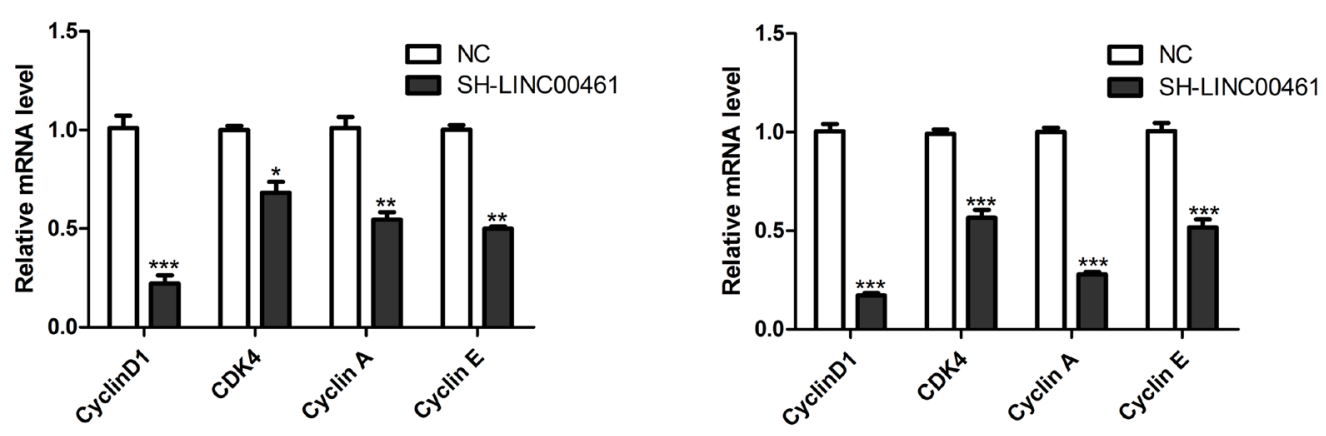

$\mathrm{D}$
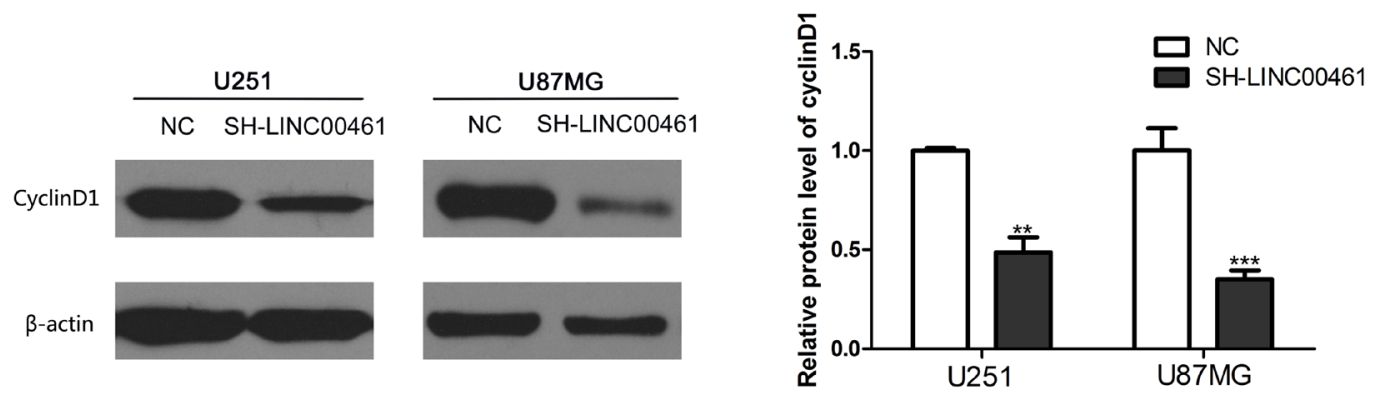

Figure 5: The knockdown of LINC00461 caused G0/G1 phase arrest and reduced expression of cyclins and CDK4. (A) After lentivirus infection, cell cycle distribution was analyzed by flow cytometry. (B) Histograms showing cell cycle phase distribution of both cells. (C) Expression levels of cyclinD1, CDK4, cyclin A and cyclin E mRNAs were measured by real-time PCR. (D) Expression levels of cyclinD1 protein were analyzed by the Western blotting. Histograms showed the quantization of Western blots (normalized by $\beta$-actin expression). Data are presented as mean \pm SEM. ${ }^{*}, P<0.05 ;{ }^{* *}, P<0.01{ }^{* * *}, P<0.001$. 
results indicated that LINC00461 might promote glioma cell proliferation, migration, and invasion through MAPK/ ERK and PI3K/AKT signaling pathways.

Studies have shown that lncRNAs can regulate genes in its vicinity via $c i s$-interaction. There are two protein-coding genes $M E F 2 C$ and TMEM161B at either side of LINC00461. LINC00461 itself also contains a microRNA miRNA-9-2, which can produce a mature
microRNA miR-9. In our study, after the knockdown of LINC00461, MEF2C mRNA levels were reduced to $82.80 \pm 2.66 \%$ in $\mathrm{U} 251(P<0.05)$ and $77.88 \pm 4.47 \%$ in U87MG cells $(P<0.01)$ (Figure $7 \mathrm{C})$. Expression levels of TMEM161B mRNA also decreased to $75.86 \pm 3.82 \%$ in U251 cells $(P<0.01)$ and $65.28 \pm 2.23 \%$ in U87MG cells $(P<0.001)$ (Figure 7C). The knockdown of LINC00461 also drastically suppressed expression levels of miR-9 to
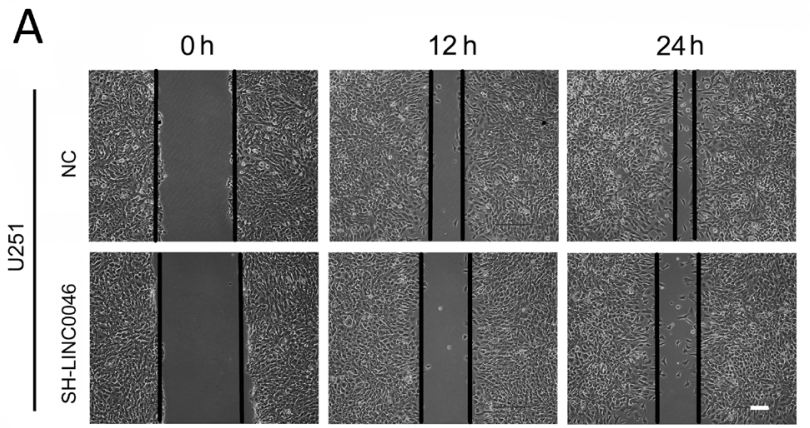

B
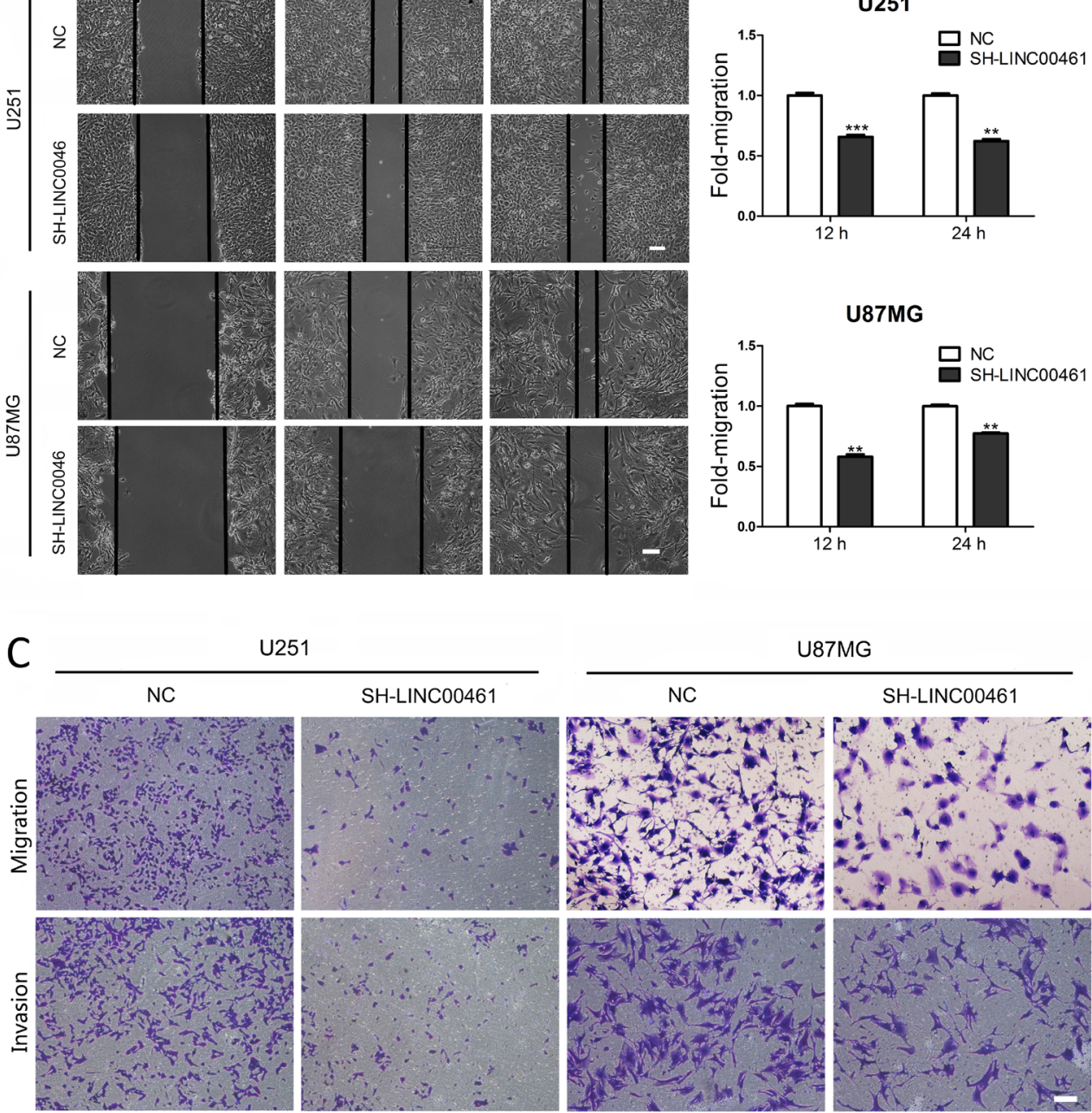

251
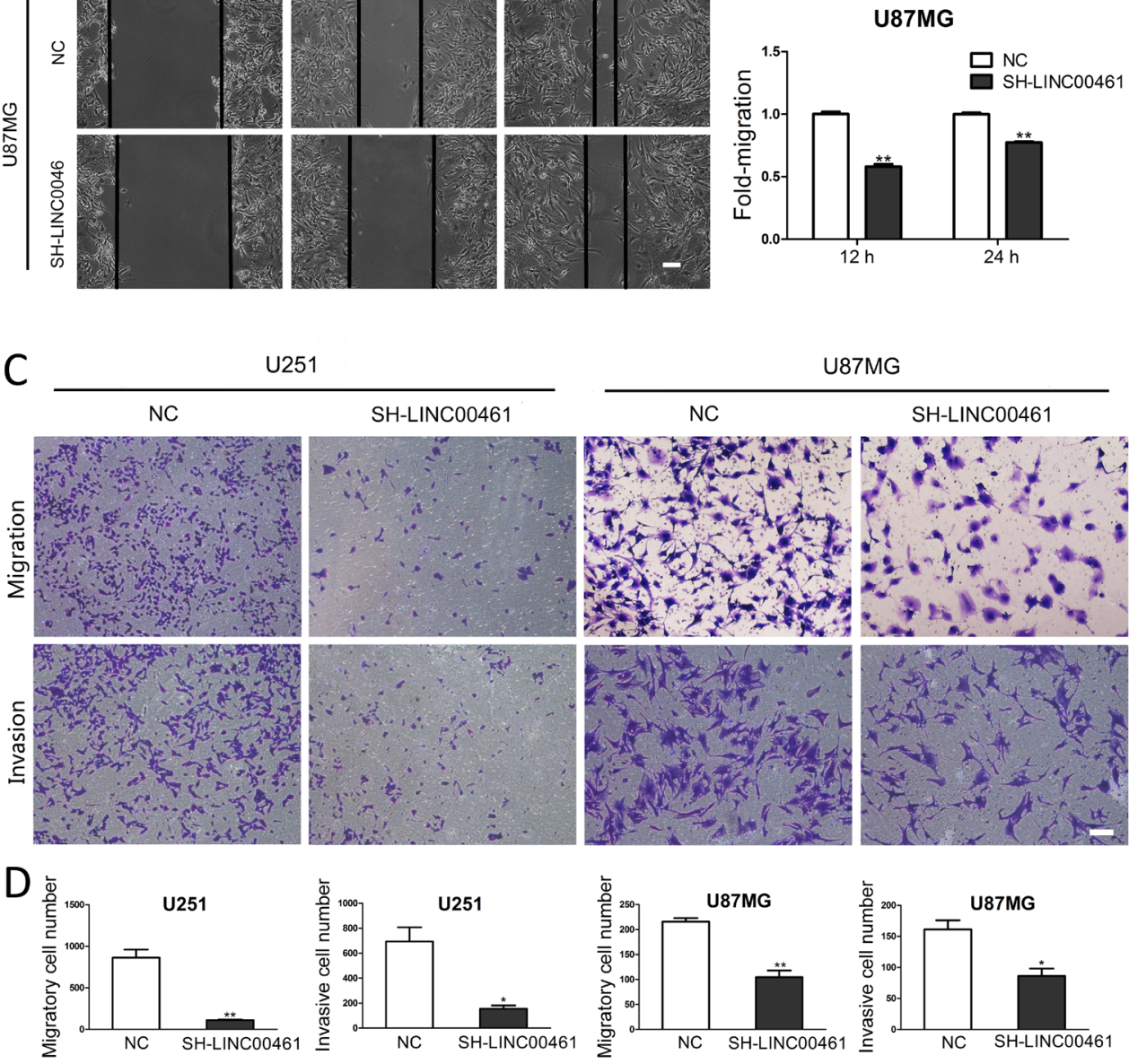

Figure 6: Down-regulation of LINC00461 inhibited cell migration and invasion. (A) The wound healing assay showed delayed gap closure in LINC00461 knockdown cells compared with that in control cells at $12 \mathrm{~h}$ and $24 \mathrm{~h}$ time points in U251 and U87MG cells. (B) Wound gaps were analyzed by measuring the distance of migrating cells. The migrating distance by control cells is set as 1 . (C) Representative images of Transwell assay showing the effect of LINC00461 knockdown on cell migration and invasion. (D) Histograms showing numbers of migratory and invasive cells. Data are presented as mean \pm SEM. ${ }^{*}, P<0.05 ;{ }^{* *}, P<0.01 ;{ }^{* * *}, P<0.001$. Scale bar: $100 \mu \mathrm{m}$. 
A

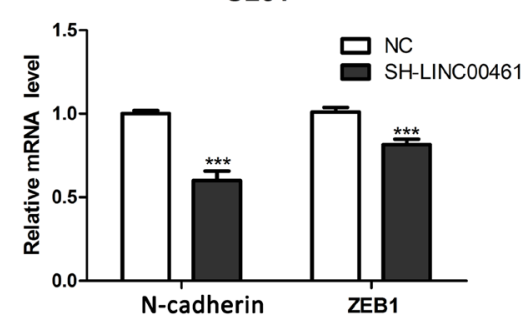

B

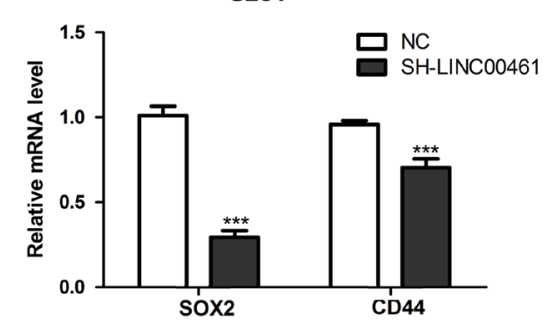

U87MG
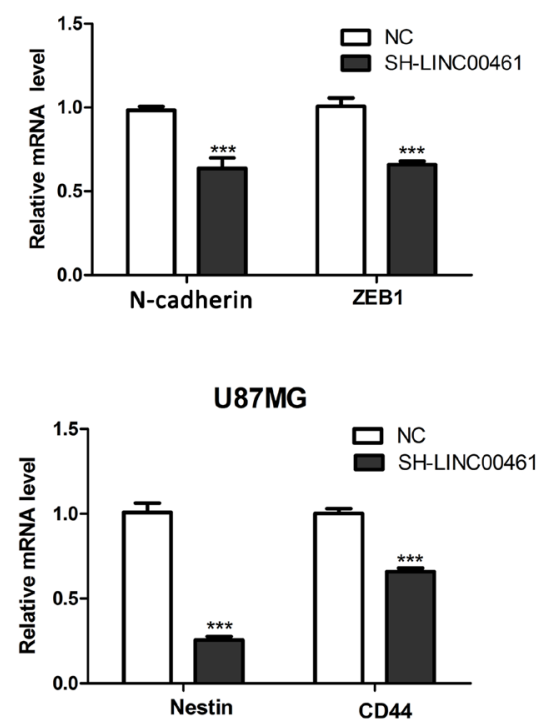

C

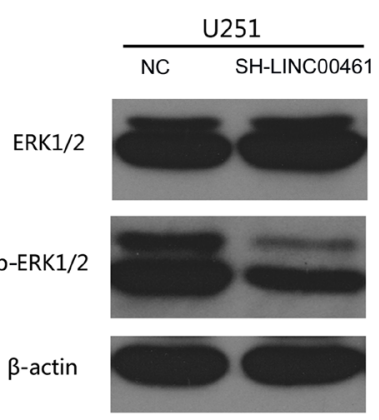

AKT

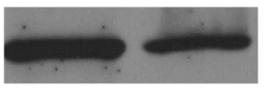

p-AKT

$\beta$-actin
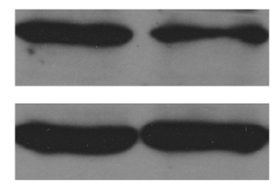

D

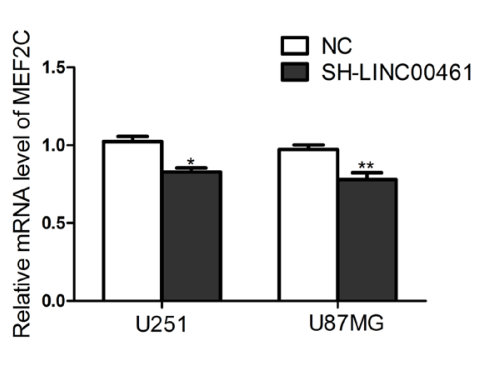

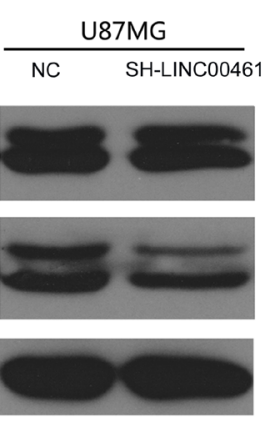
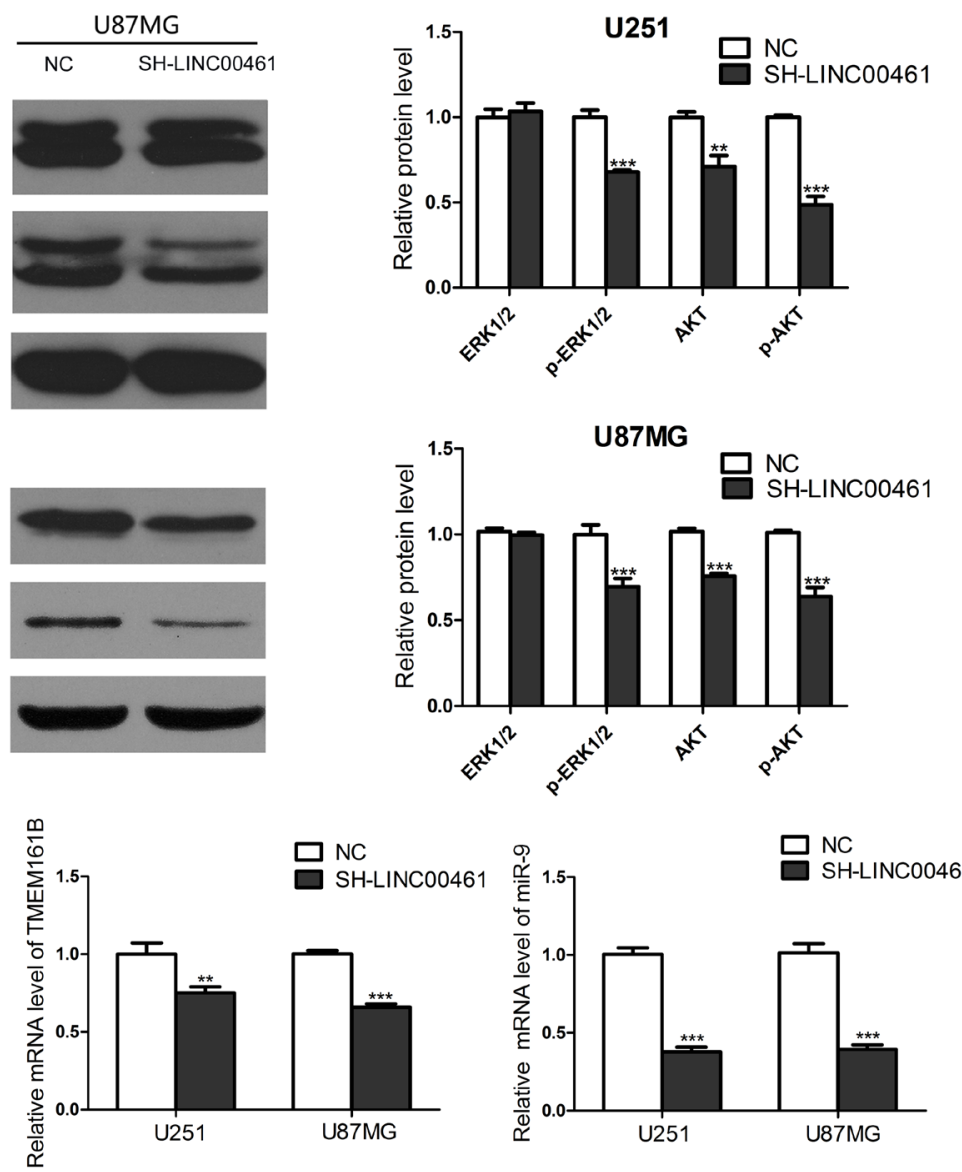

Figure 7: Mechanisms of LINC00461 promoting glioma cell proliferation, migration and invasion. (A) Expression levels of N-cadherin and ZEB1 mRNA were measured by real-time PCR. (B) Expression levels of SOX2, CD44 and Nestin mRNA were measured by real-time PCR. (C) Western blots showed that down-regulation of LINC00461 suppressed AKT, p-AKT and p-ERK1/2 in U251 and U87MG cells. Histograms showed relative mean values of protein levels from three independent experiments. (D) Analysis on expression levels of two protein-coding and one non-coding transcripts in close proximity to the LINC00461 locus. Data are presented as mean \pm SEM. ${ }^{*}, P<0.05 ;{ }^{* *}, P<0.01 ;{ }^{* * *}, P<0.001$. 
$37.71 \pm 3.08 \%$ in $\mathrm{U} 251(P<0.001)$ and $39.26 \pm 2.92 \%$ in U87MG cells $(P<0.001)$ (Figure 7C). Our data showed that LINC00461 can affect nearby genes possibly via cisinteraction.

\section{DISCUSSION}

We have identified a mouse lncRNA C130071C03Rik which is highly expressed in mouse neural tissues. Our studies showed that it is specifically expressed in mouse neural stem cells during development. Its human homolog, LINC00461, is up-regulated in human glioma tissues. We performed a series of experiments and found that LINC00461 plays multiple roles in glioma cells, affecting cell proliferation, migration, and invasion. Our results also suggested that it has little effect on cell apoptosis. The knockdown of LINC00461 caused cells being arrested during G1/S transition with concomitant decreased cyclinD1/A/E expression. We also found that LINC00461 is involved in MAPK/ERK and PI3K/AKT signaling pathways and regulates genes in its vicinity.

There are very few studies related to this lncRNA. It has been reported by Oliver et al. in 2015. They found that Visc-1 (aka. C130071C03Rik) was expressed in the cortical plate and the ventricular and subventricular zones of the telencephalon as well as the rostral and caudal interneuron migratory streams at E16.5 [27]. Their data suggested its role in cell proliferation and migration, which is consistent with our findings. LINC00461 has also been reported to be up-regulated in several types of cancers. For example, Pastori et al. have reported LINC00461 as one of the top 100 most up-regulated lncRNAs in glioblastomas [28]. Crea et al. also showed that LINC00461 is upregulated in metastatic prostate cancers [29].

In our study, we found that mouse ortholog of LINC00461 is expressed in the ventricular zone of mouse spinal cord at E11.5 and E13.5. It is also highly enriched in gliomas. Further studies revealed significant and positive correlation between LINC00461 and SOX2 mRNA in gliomas. SOX2 activity has been found to be associated with the maintenance of the undifferentiated state of cancer stem cells [30]. These results suggested that LINC00461 may regulate "stem-like" properties of neural/ cancer stem cells.

LINC00461 plays multiple functional roles in glioma cells. One of them is cell cycle regulation. The loss of the regulatory control of the cell cycle, which leads to an unrestrained cell proliferation, is a hallmark of cancer cells [31]. Our data suggested that LINC00461 knockdown could induce the G1/S transition arrest which leads to the decreased viability of glioma cells. Further, we found that suppression of LINC00461 resulted in decreased expression levels of cyclinD1/E/A and CDK4. CyclinD1 plays pivotal roles in $\mathrm{G} 1 / \mathrm{S}$ transition and is frequently over-expressed in a large number of cancers including gliomas. Its high expression is associated with the tumor malignancy and poor prognosis. CyclinD1 binds to CDK4 and CDK6 (cyclin-dependent kinase 4/6) to phosphorylate retinoblastoma protein and activate the transcription factor E2F-1. E2F-1 initiates the transcription of some cell cycle regulators, such as cyclin $\mathrm{E}$ and cyclin A, to drive the transition from G1 to S phase [32].

In most epithelial carcinomas, cancer cells usually undergo the epithelial-mesenchymal transition (EMT) to gain invasiveness and start metastasis. During the EMT process, several EMT markers or inducers, including ZEB1 and SNAIL, are activated to promote the "stemness" of cancer cells, thus induce cancer invasion [33]. In our study, we found that reduced LINC00461 expression reduced expression levels of some EMT markers (N-cadherin and ZEB1) and several other factors related to glioma "stemness" (CD44, SOX2, Nestin). Therefore, LINC00461 may participate in glioma progression via promoting EMT.

Current studies have found lncRNAs play critical roles in the progression of gliomas. HOTAIR (HOX transcript antisense intergenic RNA) has been reported to be up-regulated in gliomas. Its knockdown inhibits cell proliferation, migration, invasion, promotes apoptosis and cell cycle arrest by up-regulating miR-326 in human glioma cells [34]. Wang et al. have reported that lncRNA CRNDE (colorectal neoplasia differentially expressed) is up-regulated in gliomas and promotes glioma cell growth and invasion through mTOR signaling pathway [21]. Shi et al. have found that lncRNA H19 is closely correlated with the severity of tumors. H19 transcript can produce a miRNA (miR-675), which directly regulates CDH13 (Cadherin 13), thereby modulating glioma cell invasion [35].

In this study, we have found that LINC00461 regulates miRNA miR-9, which is the mature form of miR-9-2 gene. The sequence of miR-9-2 is included in the sequence of LINC00461. Knockdown of LINC00461 significantly suppressed expression levels of miR-9. $\mathrm{Wu}$ et al. have reported that expression levels of miR9 in gliomas are significantly higher than those in nonneoplastic brain tissues [36]. The overall survival time of glioma patients with high miR-9 expression levels is obviously shorter than that with low miR-9 expression levels [36]. Schraivogel et al. found that miR-9 promotes neurosphere-like formation of glioblastoma stem cells by targeting a tumor suppressor CAMTA1 (calmodulinbinding transcription activator 1) [37]. It has also been reported that miR-9 can promote glioma cell migration by repression of NF1 (neurofibromin1) [38]. Based on these studies and our own work, we concluded that LINC00461 might regulate glioma progression via miR-9.

Studies have shown that miR-9 could target multiple signaling pathways [39]. In ovarian cancer and gastric

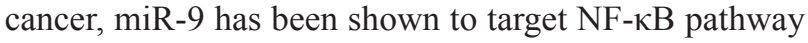
leading to inhibition of cell proliferation and metastasis $[40,41]$. On the other hand, miR-9 overexpression has been shown to enhance metastasis in esophageal 
squamous cell carcinoma by targeting E-cadherin [42]. Zhang et.al have found that overexpression miR-9 could block the phosphorylation of AKT (Ser473) and ERK [42]. In our study, we found that overexpression or inhibitor of miR-9 has no effects on AKT and ERK in glioma cells (Supplementary Figure 4). Further studies are needed to decipher the mechanism of miR-9 regulation on gliomas.

Recent studies have found that long intergenic non-coding RNAs (lincRNAs) can regulate expression levels of protein-coding genes in their vicinity [43]. We found that LINC00461 is important for the expression of neighbor genes, TMEM161B and $M E F 2 C$, possibly via cis-interaction. Expression levels of both genes decreased after the treatment of LINC00461 shRNA. The function of TMEM161B is still not clear, while MEF2C has been reported to play an anti-apoptotic role, protecting the differentiating cells from death during neurogenesis [44], and promote neuronal synapse formation [45, 46]. Li et al. showed that Mef2c knockout in Nestinexpressing neural stem/progenitor cells (NSCs) impaired neuronal differentiation in vivo, resulting in aberrant cell compaction and smaller somal size. However, the proliferation and survival of NSCs were not affected [47]. Still no reports have been published about effects of $\mathrm{MEF} 2 \mathrm{C}$ on gliomas.

Previous studies have shown that several signaling pathways are involved in gliomas [48]. Among them, MAPK/ERK and PI3K/AKT are two frequently activated pathways [49, 50]. ERK1/2 (Extracellular signal-regulated kinases 1 and 2) belong to the mitogen-activated protein kinase (MAPK) family and play crucial roles in a wide range of biological processes, including cell proliferation, differentiation, and motility. They have been reported to be activated in glioblastomas [51]. Meanwhile, elevated AKT phosphorylation levels have been observed in $84 \%$ cases of glioblastomas [52]. The PI3K/AKT signaling pathway plays fundamental roles in regulating cellular processes such as cell proliferation, survival, and migration [53]. Our studies found that LINC00461 positively affects both MAPK/ERK and PI3K/AKT pathways. Knockdown of LINC00461 can suppress not only phosphorylation levels of ERK1/2 and AKT proteins, but also total AKT protein

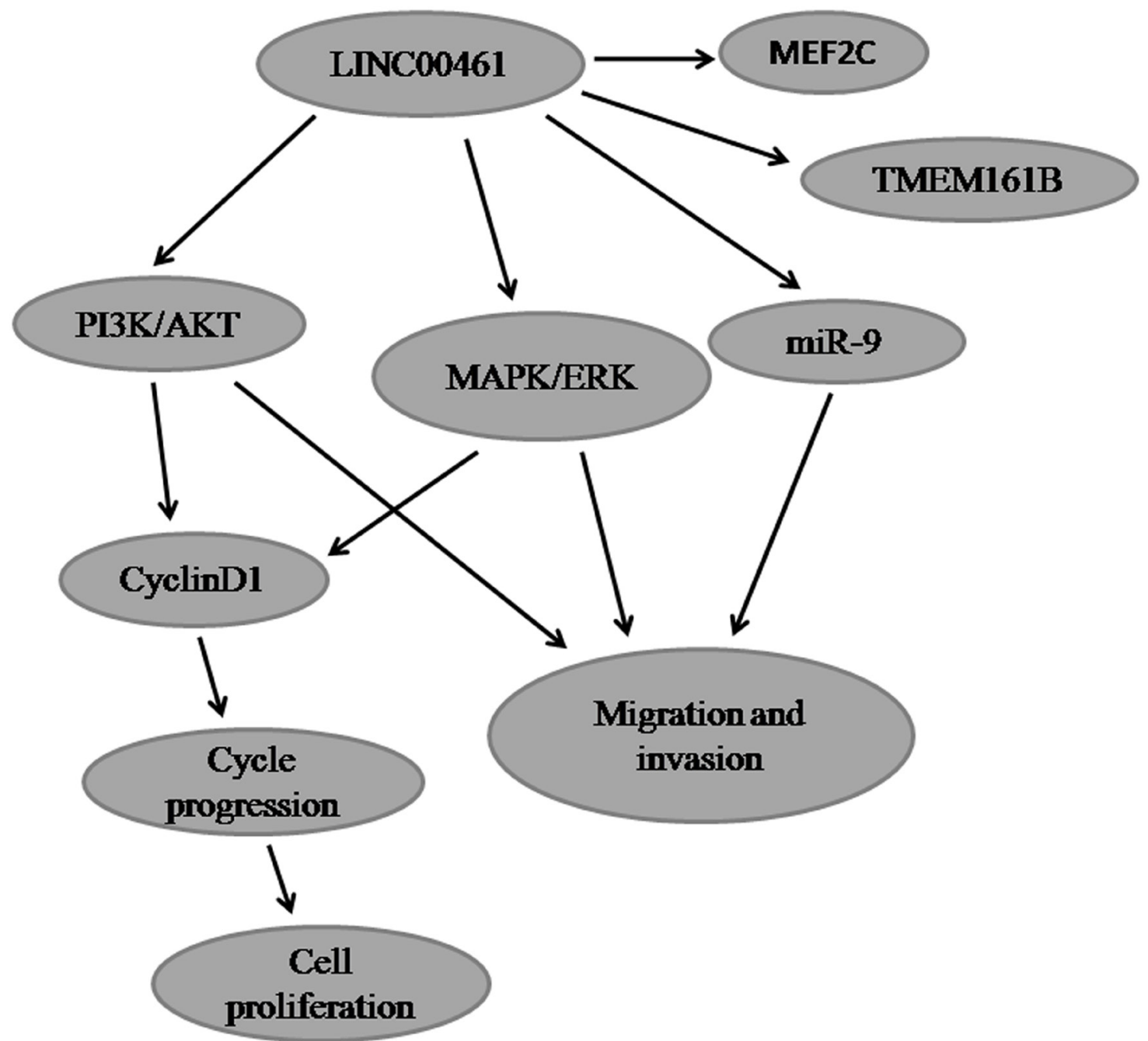

Figure 8: The cartoon of the mechanism underlying the regulation of LINC00461 on glioma cells. 
Table 1: Sequences of real-time PCR primers

\begin{tabular}{lcc}
\hline & Forward (5' to 3') & Reverse (5' to 3') \\
\hline AP3B1 & GAAGCGGATTGTTGGGATGAT & TCAGCATATCGAACCAGGTAAAC \\
C130071C03Rik & CATTTCCCACCCACAGCCATCT & CTCTTGGCACCCTTCCACTTG \\
CD44 & CTGCCGCTTTGCAGGTGTA & CATTGTGGGCAAGGTGCTATT \\
CDK4 & ATGGCTACCTCTCGATATGAGC & CATTGGGGACTCTCACACTCT \\
CDK6 & CCAGATGGCTCTAACCTCAGT & AACTTCCACGAAAAAGAGGCTT \\
CyclinA & CGCTGGCGGTACTGAAGTC & GAGGAACGGTGACATGCTCAT \\
CyclinD1 & TGCGAAGTGGAAACCATCCG & AGGAAGCGGTCCAGGTAGTT \\
CyclinE & GCCAGCCTTGGGACAATAATG & CTTGCACGTTGAGTTTGGGT \\
GAPDH & GGGAGCCAAAAGGGTCATCA & TGATGGCATGGACTGTGGTC \\
LINC00461 & GACATTTACGCCACAACCCACG & AGACAGACCCTCAGATTCCCCA \\
MEF2C & TTCACTGTTGTGCTCCTTTGC & CGGGTCTGTCCAAGCATCTAT \\
N-cadherin & AGCCAACCTTAACTGAGGAGT & GGCAAGTTGATTGGAGGGATG \\
Nestin & CTGCTACCCTTGAGACACCTG & GGGCTCTGATCTCTGCATCTAC \\
ONECUT2 & CAAACGCCCGTCAAAGGAGAT & GCTCAGATCGTCTTGCCACTT \\
SOX2 & TACAGCATGTCCTACTCGCAG & GAGGAAGAGGTAACCACAGGG \\
TMEM161B & AAGAAAGAAGCGGGGCGAAT & GCAGAGTTGTGTGAAGCAGC \\
ZEB1 & CAGCTTGATACCTGTGAATGGG & TATCTGTGGTCGTGTGGGACT \\
\hline
\end{tabular}

The $2^{-\Delta \Delta \mathrm{Ct}}$ method was applied to analyze real-time PCR results.

levels. Dual activation of MAPK/ERK and PI3K/AKT signaling pathways has been reported in many types of cancers. In thyroid cancers, both MAPK/ERK and PI3K/ AKT pathways are reported to be activated, which play fundamental roles in promoting cell growth, survival and are associated with tumorigenesis $[54,55]$. Lv et al. found that CXCR4 knockdown repressed glioma cell migration via deactivation of both ERK and PI3K/AKT pathways [56]. Our laboratory previously has found that TCF3 (transcription factor 3) can activate both MAPK/ERK and PI3K/AKT signaling pathways to suppress cell apoptosis and promote cell migration [57]. These data suggested that LINC00461 might promote glioma cell proliferation, migration, and invasion via both MAPK/ERK and PI3K/ AKT signaling pathways (Figure 8).

It is worthwhile to note that cyclinD1 can be regulated by a number of signaling pathways, including PI3K/AKT and ERK1/2 pathways. PI3K/AKT pathway can promote cyclinD1 expression and positively regulates G1/S cell cycle progression through deactivation of GSK3bata [58]. In addition, persistent activation of ERK1/2 is required to pass the G1 restriction point in fibroblasts [59, 60]. Our data suggested that LINC00461 can activate both MAPK/ERK and PI3K/AKT signaling pathways which lead to cyclinD1 activation and cell proliferation (Figure $8)$.
In summary, our studies suggested that IncRNA LINC00461 plays important roles in gliomas via recruiting multiple pathways. Based on these studies, LINC00461 could be a potential target in glioma diagnosis and treatment.

\section{MATERIALS AND METHODS}

\section{Human tissues}

Glioma gene expression data were downloaded from the Gene Expression Omnibus Web site (http:// www.ncbi.nlm.gov/geo/, GSE16011 and GSE4290). GSE16011 dataset contains 276 glioma samples (8 samples of grade I, 24 samples of grade II, 85 samples of grade III and 159 samples of grade IV) and 8 samples of nonneoplastic brain tissues. GSE4290 dataset contains 157 glioma samples (45 samples of grade II, 31 samples of grade III, and 81 samples of grade IV) and 23 samples of nonneoplastic brain tissues. Chinese gliomas and nonneoplastic brain tissues were collected from the Department of Neurosurgery, Renmin Hospital of Wuhan University from year 2013 to 2015. Informed consent was obtained from each patient. The study was approved by the Institutional Research Board of Renmin Hospital. No prior treatments had been given to these patients. Samples were examined and verified by pathologists. All specimens 
were immediately frozen in liquid nitrogen after resection and kept in liquid nitrogen for storage. Chinese glioma specimens included 9 samples of grade II, 5 samples of grade III and 5 samples of grade IV. Five cases of nonneoplastic brain samples were collected from patients with cerebral trauma.

\section{Cell culture}

U251 and U87MG human glioma cells were maintained in alpha-modification of eagle's medium ( $\alpha$-MEM) or Dulbecco's Modified Eagle Medium (DMEM) with high glucose (Hyclone, USA) and supplemented with $10 \%$ fetal bovine serum (Sigma, USA). Cells were kept in an incubator at $37^{\circ} \mathrm{C}$, a minimum relative humidity of $95 \%$, and atmosphere of $5 \% \mathrm{CO}_{2}$ in air.

\section{RNA extraction, reverse-transcription and real- time PCR}

Total RNA from tissues or cells was extracted with Trizol reagent (Invitrogen, USA) under the manufacturer's instruction. RNA concentration was measured by NanoDrop-2000 (Thermo Fisher, USA). $2.5 \mu \mathrm{g}$ of total RNA was used for cDNA synthesis with RevertAid First Strand cDNA Synthesis kit (Thermo Fisher, USA). Expression levels of mature miR-9 were detected by the Bulge-LoopTM miRNA q-RT-PCR primer kits (RiboBio, Guangzhou, China). Roche light Cycler 480 mix (Roche, Mannheim, Germany) was employed to perform real-time PCR on a CFX 96 Real-Time PCR Detection System (Biorad, USA). GAPDH mRNA or U6 snRNA was used as the internal control. Sequences of real-time PCR primers were listed in Table 1.

\section{In site hybridization}

C57BL/6 mouse spinal cords and brains were fixed in $4 \%$ paraformaldehyde (PFA) at $4^{\circ} \mathrm{C}$ overnight. Targeted sequences for riboprobes were amplified by PCR and cloned into pBLUE-T plasmid (Zoman, Beijing, China). Primer sequences for riboprobe cloning were: C130071C03Rik forward 5'-CCGAAGACTTAGAGCTAGCAGG-3', reverse 5'TCACAAGGCCCTAACCACATAC-3', LINC00461 forward 5'-TCTCTGTTCCAAGAGGGTTTCC-3', reverse 5'-GCTGTTTCCTGGATAGACCTGAT-3'. Protocols for tissue preparation and in situ hybridization with digoxigenin-labeled probes have been previously described [61].

\section{Lentivirus preparation}

Annealed DNA fragments containing either scrambled sequences or short-hairpin RNA (shRNA) sequences targeting LINC00461 were cloned into plasmid PLKO.1 ZSGreen (Anti-hela biotech, Xiamen,
China). Then, PLKO.1 vector was co-transfected with pMD2.G and psPAX2 plasmids into HEK293T cells using Neofect DNA transfection reagent (Neofect Tech, Beijing, China). ShRNA targeting sequences were: shLINC00461 5'-GGAAATGAAAGTGACATTTAC-3', the second shRNA shRNA\#2: 5'-GGAAGCTACTGAAGCAGAAAG-3', and scrambled sequences 5'- CCTAAGGTTAAGTCGCCCTCG-3'. The scrambled sequences were used as the negative control (NC) for shRNA knockdown experiments.

\section{MiRNA transfection}

MiR-9 mimics, non-specific control, miR-9 inhibitor, and random sequence were all purchased from RiboBio (Guangzhou, China). Cells were transfected at $40-60 \%$ confluence using Neofect siRNA transfection reagent (Neofect Tech, Beijing, China).

\section{Western blotting analysis}

$48 \mathrm{~h}$ after lentivirus infection, total protein was extracted from cells by RIPA cell lysis buffer with proteinase and phosphatase inhibitors. The supernatant of lysates was collected and electrophoresed in 10\%-12\% SDS-PAGE gel, then transferred onto PVDF membranes. Membranes were blocked in Tris-buffered saline plus $0.1 \%$ Tween-20 (TBST) with 5\% non-fat dry milk or bovine serum albumin (BSA) at room temperature for $1 \mathrm{~h}$, followed by primary antibody incubation at $4{ }^{\circ} \mathrm{C}$ overnight. On the next day after washing with TBST, membranes were incubated with secondary antibodies labeled with HRP at room temperature for $1 \mathrm{~h}$. Then proteins were detected by ECL detection system (P1010, Applygen Technology, Beijing, China). Protein levels were measured by Image $\mathrm{J}$ software. Primary antibodies were listed as follows: caspase-3(No. 9662, 1:1000, Cell Signaling Technology), cleaved caspase-3 (No. AF7022, 1:1000, Affinity Biosciences); ERK1/2 antibody (No.4695, 1:1000, Cell Signaling Technology); p-ERK1/2 (Thr202/ Tyr204) antibody (No. 4370, 1:1000, Cell Signaling Technology); AKT (No. 9272, 1:1000, Cell Signaling Technology), p-AKT (Ser473) antibody (No. 9271,1:1000, Cell Signaling Technology); cyclinD1 (AB134175, 1:20000,Abcam); $\beta$-actin (No. 10494-1-AP, 1:10000, Proteintech, Beijing, China).

\section{CCK-8 assay}

The CCK-8 cell counting kit (Zoman, Beijing, China) was used to determine the cell viability. U251 or U87MG cells were infected with lentivirus for $48 \mathrm{~h}$. Then, cells were seeded onto 96-well plates at the density of $2 \mathrm{x}$ $10^{3}$ cells per well for measurement at time points of 1 day (d), 2d, 3d, 4d and 5d after lentivirus infection. At each time point, $10 \mu \mathrm{l}$ CCK-8 solution was added into each well. After $1 \mathrm{~h}$ incubation at $37^{\circ} \mathrm{C}$, optical density (OD) at 450 
nm was measured by a microplate reader (EXL800 from BioTek, Winooski, Vermont, USA).

\section{Wound healing assay}

U251 and U87MG cells were seeded in 6-well plates at a density of $2 \times 10^{5}$ cells per well. $48 \mathrm{~h}$ after lentivirus infection, the cell layer was wounded by a sterile $10 \mu \mathrm{l}$ pipette tip. Cells were washed three times with PBS to remove floating cells. Then cells were allowed to grow for 24 hours. The wound closure was observed by a light microscope at x100 magnification. Images of three random fields were captured at $0 \mathrm{~h}, 12 \mathrm{~h}$, and $24 \mathrm{~h}$ time points post wounding.

\section{Cell migration and invasion assays}

Twenty-four-well plates and Transwell chambers (pore size at $8 \mu \mathrm{m}$ ) (corning, New York, USA) were used for cell migration and invasion experiments. For the migration assay, $48 \mathrm{~h}$ after lentivirus infection, 200 $\mu \mathrm{l}$ of serum-free medium containing $1 \times 10^{5}$ cells was added to the upper chamber, and $600 \mu \mathrm{l}$ of medium with $20 \%$ serum was added to the lower chamber as a chemoattractant. Cells were incubated for another $20 \mathrm{~h}$ at $37^{\circ} \mathrm{C}$ before measurement. For the invasion assay, the upper chamber was pretreated with $50 \mu$ matrigel (BD Bioscience, San Jose, USA) for $4 \mathrm{~h}$ at $37^{\circ} \mathrm{C}$. Then, 200 $\mu \mathrm{l}$ of serum-free medium containing $2 \times 10^{5}$ cells was added to the upper chamber, while $600 \mu l$ medium with $20 \%$ serum to the lower chamber. Cells were incubated for another $30 \mathrm{~h}$ at $37^{\circ} \mathrm{C}$. After the incubation, cells in top chambers were removed by a cotton swab. Cells on the lower surface of the insert were fixed in 4\% PFA for $15 \mathrm{~min}$, and stained with $0.1 \%$ crystal violet for $30 \mathrm{~min}$. An optical microscope was used to visualize stained cells in five random fields.

\section{EdU assay}

EdU assay kit (Ribobio, Guangzhou, China) was used to detect cell proliferation. $6 \times 10^{3}$ cells were cultured for each well in 24-well plates. $48 \mathrm{~h}$ after lentivirus infection, $200 \mu \mathrm{l}$ of $50 \mu \mathrm{M}$ EdU solution was added into each well. Cells were cultured for another $2 \mathrm{~h}$. Afterward, cells were fixed with 4\% PFA for $30 \mathrm{~min}$, and incubated in $100 \mu \mathrm{l}$ PBS with $0.5 \%$ tritonX-100 for $10 \mathrm{~min}$. Then cells were incubated with Apollo solution (Ribobio, Guangzhou, China) for $30 \mathrm{~min}$, followed by DAPI staining for nuclei. EdU-labeled cells were counted manually in ten random fields from each well.

\section{Immunofluorescence}

Cells were fixed with 4\% PFA and washed with PBST. Then cells were blocked in PBS with 5\% normal goat serum at room temperature for $1 \mathrm{~h}$. Samples were then incubated with the primary antibody against Ki67 (No. 14-5698, 1:200, eBioscience, San Diego, USA) at $4^{\circ} \mathrm{C}$ for overnight. On the next day after washing with PBS, slides were incubated with the secondary antibody (No. A23340, 1:500, Abbkine, USA) at room temperature for $1 \mathrm{~h}$. Afterward, slides were mounted with anti-fade mounting medium (with DAPI) and observed under an epifluorescence microscope.

\section{Apoptosis analysis}

Annexin V-PE /7-AAD apoptosis detection kit (Keygen Biotech, Nanjing, China) was used to analyze cell apoptosis. Cells were washed with ice-cold PBS and stained with annexin-V and 7-AAD. Apoptotic cells were quantified by a dual-color flow cytometry machine (FACS Aria III, BD Biosciences, San Jose, CA, USA). Ten thousand cells were counted per sample. Data were analyzed by Flowjo 7.6 software.

\section{Cell cycle analysis}

The content of DNA was detected by a cell cycle detection kit (Keygen biotech, Nanjing, China). $48 \mathrm{~h}$ after lentivirus infection, U251 and U87MG cells were harvested in ice-cold PBS, then fixed with 70\% cold ethyl alcohol at $4{ }^{\circ} \mathrm{C}$ for overnight. Fixed cells were incubated with RNAse A for $30 \mathrm{~min}$ and stained with propidium iodide (PI) for $30 \mathrm{~min}$ in the darkness. Stained cells were measured by flow cytometry (FACS Aria III, BD Biosciences, San Jose, CA, USA). Data were analyzed with a cell-cycle program (Modfit) to calculate percentages of cells at G0/G1, G2/M and S phases.

\section{Statistical analysis}

All experiments were performed for at least three times independently. All data were presented as mean \pm SEM. SPSS 19.0 and Prism 5.0 statistical softwares were employed for the analysis. Corresponding significance levels were indicated in each figure.

\section{ACKNOWLEDGMENTS}

This work was supported by grants from the Natural Science Foundation of China (No. 81371338), intramural funding from Wuhan University (No.2042016kf0181), Wuhan Health and Family Planning Commission foundation of key project of clinic medical research (No. WX15A10) and Doctoral Foundation of The Central Hospital of Wuhan (No. YB14A02).

\section{CONFLICTS OF INTEREST}

The authors declared that they have no competing interests. 


\section{REFERENCES}

1. Rinn JL, Chang HY. Genome regulation by long noncoding RNAs. Annu Rev Biochem. 2012; 81:145-166.

2. Shi X, Sun M, Liu H, Yao Y, Song Y. Long non-coding RNAs: a new frontier in the study of human diseases. Cancer Lett. 2013; 339:159-166.

3. Wang KC, Chang HY. Molecular mechanisms of long noncoding RNAs. Mol Cell. 2011; 43:904-914.

4. Lee JT. Epigenetic regulation by long non-coding RNAs. Science. 2012; 338:1435-1439.

5. Tian D, Sun S, Lee JT. The long noncoding RNA, Jpx, is a molecular switch for $\mathrm{X}$ chromosome inactivation. Cell. 2010; 143:390-403.

6. Sleutels F, Zwart R, Barlow DP. The non-coding Air RNA is required for silencing autosomal imprinted genes. Nature. 2002; 415:810-813.

7. Mattick JS, Amaral PP, Dinger ME, Mercer TR, Mehler MF. RNA regulation of epigenetic processes. Bioessays. 2009; 31:51-59.

8. Wapinski O, Chang HY. Long noncoding RNAs and human disease. Trends Cell Biol. 2011; 21:354-361.

9. Wang Y, He L, Du Y, Zhu P, Huang G, Luo J, Yan X, Ye B, Li C, Xia P, Zhang G, Tian Y, Chen R, Fan Z. The long noncoding RNA lncTCF7 promotes self-renewal of human liver cancer stem cells through activation of Wnt signaling. Cell Stem Cell. 2015; 16:413-425.

10. Ramos AD, Andersen RE, Liu SJ, Nowakowski TJ, Hong SJ, Gertz CC, Salinas RD, Zarabi H, Kriegstein AR, Lim DA. The long noncoding RNA Pnky regulates neuronal differentiation of embryonic and postnatal neural stem cells. Cell Stem Cell. 2015; 16:439-447.

11. Moran VA, Perera RJ, Khalil AM. Emerging functional and mechanistic paradigms of mammalian long non-coding RNAs. Nucleic Acids Res. 2012; 40:6391-6400.

12. Xu SP, Zhang JF, Sui SY, Bai NX, Gao S, Zhang GW, Shi QY, You ZL, Zhan C, Pang D. Downregulation of the long noncoding RNA EGOT correlates with malignant status and poor prognosis in breast cancer. Tumour Biol. 2015; 36:9807-9812.

13. Tuo YL, Li XM, Luo J. Long noncoding RNA UCA1 modulates breast cancer cell growth and apoptosis through decreasing tumor suppressive miR-143. Eur Rev Med Pharmacol Sci. 2015; 19:3403-3411.

14. Kogo R, Shimamura T, Mimori K, Kawahara K, Imoto S, Sudo T, Tanaka F, Shibata K, Suzuki A, Komune S, Miyano $\mathrm{S}$, Mori M. Long noncoding RNA HOTAIR regulates polycomb-dependent chromatin modification and is associated with poor prognosis in colorectal cancers. Cancer Res. 2011; 71:6320-6326.

15. Li T, Xie J, Shen C, Cheng D, Shi Y, Wu Z, Deng X, Chen H, Shen B, Peng C, Li H, Zhan Q, Zhu Z. Amplification of long noncoding RNA ZFAS1 promotes metastasis in hepatocellular carcinoma. Cancer Res. 2015; 75:3181-3191.
16. Deng L, Yang SB, Xu FF, Zhang JH. Long noncoding RNA CCAT1 promotes hepatocellular carcinoma progression by functioning as let-7 sponge. J Exp Clin Cancer Res. 2015; $34: 18$.

17. Yuan SX, Tao QF, Wang J, Yang F, Liu L, Wang LL, Zhang J, Yang Y, Liu H, Wang F, Sun SH, Zhou WP. Antisense long non-coding RNA PCNA-AS1 promotes tumor growth by regulating proliferating cell nuclear antigen in hepatocellular carcinoma. Cancer Lett. 2014; 349:87-94.

18. Cheng W, Zhang Z, Wang J. Long noncoding RNAs: new players in prostate cancer. Cancer Lett. 2013; 339:8-14.

19. Misawa A, Takayama K, Urano T, Inoue S. Androgeninduced long noncoding RNA (lncRNA) SOCS2-AS1 promotes cell growth and inhibits apoptosis in prostate cancer cells. J Biol Chem. 2016; 291:17861-17880.

20. Hu T, Lu YR. BCYRN1, a c-MYC-activated long noncoding RNA, regulates cell metastasis of non-small-cell lung cancer. Cancer Cell Int. 2015; 15:36.

21. Wang Y, Wang Y, Li J, Zhang Y, Yin H, Han B. CRNDE, a long-noncoding RNA, promotes glioma cell growth and invasion through mTOR signaling. Cancer Lett. 2015; 367:122-128.

22. Wang J, Zhou Y, Lu J, Sun Y, Xiao H, Liu M, Tian L. Combined detection of serum exosomal miR-21 and HOTAIR as diagnostic and prognostic biomarkers for laryngeal squamous cell carcinoma. Med Oncol. 2014; 31:148.

23. Goodenberger ML, Jenkins RB. Genetics of adult glioma. Cancer Genet. 2012; 205:613-621.

24. Louis DN, Ohgaki H, Wiestler OD, Cavenee WK, Burger PC, Jouvet A, Scheithauer BW, Kleihues P. The 2007 WHO classification of tumours of the central nervous system. Acta Neuropathol. 2007; 114:97-109.

25. Thakkar JP, Dolecek TA, Horbinski C, Ostrom QT, Lightner DD, Barnholtz-Sloan JS, Villano JL. Epidemiologic and molecular prognostic review of glioblastoma. Cancer Epidemiol Biomarkers Prev. 2014; 23:1985-1996.

26. Davis ME. Glioblastoma: overview of disease and treatment. Clin J Oncol Nurs. 2016; 20:S2-S8.

27. Oliver PL, Chodroff RA, Gosal A, Edwards B, Cheung AF, Gomez-Rodriguez J, Elliot G, Garrett LJ, Lickiss T, Szele F, Green ED, Molnar Z, Ponting CP. Disruption of Visc-2, a brain-expressed conserved long noncoding RNA, does not elicit an overt anatomical or behavioral phenotype. Cereb Cortex. 2015; 25:3572-3585.

28. Pastori C, Kapranov P, Penas C, Peschansky V, Volmar CH, Sarkaria JN, Bregy A, Komotar R, St Laurent G, Ayad NG, Wahlestedt C. The Bromodomain protein BRD4 controls HOTAIR, a long noncoding RNA essential for glioblastoma proliferation. Proc Natl Acad Sci U S A. 2015; 112:8326-8331.

29. Crea F, Watahiki A, Quagliata L, Xue H, Pikor L, Parolia A, Wang Y, Lin D, Lam WL, Farrar WL, Isogai T, Morant $\mathrm{R}$, Castori-Eppenberger $\mathrm{S}$, et al. Identification of a long 
non-coding RNA as a novel biomarker and potential therapeutic target for metastatic prostate cancer. Oncotarget. 2014; 5:764-774. https://doi.org/10.18632/oncotarget.1769.

30. Garros-Regulez L, Garcia I, Carrasco-Garcia E, Lantero A, Aldaz P, Moreno-Cugnon L, Arrizabalaga O, Undabeitia J, Torres-Bayona S, Villanua J, Ruiz I, Egana L, Sampron $\mathrm{N}$, Matheu A. Targeting SOX2 as a therapeutic strategy in glioblastoma. Front Oncol. 2016; 6:222.

31. Bernardi A, Frozza RL, Hoppe JB, Salbego C, Pohlmann AR, Battastini AM, Guterres SS. The antiproliferative effect of indomethacin-loaded lipid-core nanocapsules in glioma cells is mediated by cell cycle regulation, differentiation, and the inhibition of survival pathways. Int J Nanomedicine. 2013; 8:711-728.

32. Tashiro E, Tsuchiya A, Imoto M. Functions of cyclin D1 as an oncogene and regulation of cyclin D1 expression. Cancer Sci. 2007; 98:629-635

33. Lee KH, Ahn EJ, Oh SJ, Kim O, Joo YE, Bae JA, Yoon S, Ryu HH, Jung S, Kim KK, Lee JH, Moon KS. KITENIN promotes glioma invasiveness and progression, associated with the induction of EMT and stemness markers. Oncotarget. 2015; 6:3240-3253. https://doi.org/10.18632/ oncotarget.3087.

34. Ke J, Yao YL, Zheng J, Wang P, Liu YH, Ma J, Li Z, Liu XB, Li ZQ, Wang ZH, Xue YX. Knockdown of long non-coding RNA HOTAIR inhibits malignant biological behaviors of human glioma cells via modulation of miR-326. Oncotarget. 2015; 6:21934-21949. https://doi. org/10.18632/oncotarget.4290.

35. Shi Y, Wang Y, Luan W, Wang P, Tao T, Zhang J, Qian J, Liu N, You Y. Long non-coding RNA H19 promotes glioma cell invasion by deriving miR-675. PLoS One. 2014; 9:e86295.

36. Wu Z, Wang L, Li G, Liu H, Fan F, Li Z, Li Y, Gao G. Increased expression of microRNA-9 predicts an unfavorable prognosis in human glioma. Mol Cell Biochem. 2013; 384:263-268.

37. Schraivogel D, Weinmann L, Beier D, Tabatabai G, Eichner A, Zhu JY, Anton M, Sixt M, Weller M, Beier CP, Meister G. CAMTA1 is a novel tumour suppressor regulated by miR-9/9* in glioblastoma stem cells. EMBO J. 2011; 30:4309-4322.

38. Tan X, Wang S, Yang B, Zhu L, Yin B, Chao T, Zhao J, Yuan J, Qiang B, Peng X. The CREB-miR-9 negative feedback minicircuitry coordinates the migration and proliferation of glioma cells. PLoS One. 2012; 7:e49570.

39. Seashols-Williams SJ, Budd W, Clark GC, Wu Q, Daniel R, Dragoescu E, Zehner ZE. miR-9 acts as an oncomiR in prostate cancer through multiple pathways that drive tumour progression and metastasis. PLoS One. 2016; 11:e0159601.

40. Huang X, Teng Y, Yang H, Ma J. Propofol inhibits invasion and growth of ovarian cancer cells via regulating miR-9/ NF-kappaB signal. Braz J Med Biol Res. 2016; 49:e5717.

41. Sokolova O, Naumann M. NF- $\mathrm{BB}$ signaling in gastric cancer. Toxins (Basel). 2017; 9:E119.
42. Zhang J, Cheng J, Zeng Z, Wang Y, Li X, Xie Q, Jia J, Yan Y, Guo Z, Gao J, Yao M, Chen X, Lu F. Comprehensive profiling of novel microRNA-9 targets and a tumor suppressor role of microRNA-9 via targeting IGF2BP1 in hepatocellular carcinoma. Oncotarget. 2015; 6:4204042052. https://doi.org/10.18632/oncotarget.5969.

43. Mustafi D, Kevany BM, Bai X, Maeda T, Sears JE, Khalil AM, Palczewski K. Evolutionarily conserved long intergenic non-coding RNAs in the eye. Hum Mol Genet. 2013; 22:2992-3002.

44. Okamoto S, Krainc D, Sherman K, Lipton SA. Antiapoptotic role of the p38 mitogen-activated protein kinase-myocyte enhancer factor 2 transcription factor pathway during neuronal differentiation. Proc Natl Acad Sci U S A. 2000; 97:7561-7566.

45. Flavell SW, Cowan CW, Kim TK, Greer PL, Lin Y, Paradis S, Griffith EC, Hu LS, Chen C, Greenberg ME. Activitydependent regulation of MEF2 transcription factors suppresses excitatory synapse number. Science. 2006; 311:1008-1012.

46. Shalizi A, Gaudilliere B, Yuan Z, Stegmuller J, Shirogane T, Ge Q, Tan Y, Schulman B, Harper JW, Bonni A. A calciumregulated MEF2 sumoylation switch controls postsynaptic differentiation. Science. 2006; 311:1012-1017.

47. Li H, Radford JC, Ragusa MJ, Shea KL, McKercher SR, Zaremba JD, Soussou W, Nie Z, Kang YJ, Nakanishi N, Okamoto S, Roberts AJ, Schwarz JJ, Lipton SA. Transcription factor MEF2C influences neural stem/ progenitor cell differentiation and maturation in vivo. Proc Natl Acad Sci U S A. 2008; 105:9397-9402.

48. Nakada M, Kita D, Watanabe T, Hayashi Y, Teng L, Pyko IV, Hamada J. Aberrant signaling pathways in glioma. Cancers (Basel). 2011; 3:3242-3278.

49. Guo G, Yao W, Zhang Q, Bo Y. Oleanolic acid suppresses migration and invasion of malignant glioma cells by inactivating MAPK/ERK signaling pathway. PLoS One. 2013; 8:e72079.

50. Jiang L, Wang C, Lei F, Zhang L, Zhang X, Liu A, Wu G, Zhu J, Song L. miR-93 promotes cell proliferation in gliomas through activation of PI3K/Akt signaling pathway. Oncotarget. 2015; 6:8286-8299. https://doi.org/10.18632/ oncotarget. 3221.

51. Lama G, Mangiola A, Anile C, Sabatino GA, Bonis PD, Lauriola L, Giannitelli G, Torre G, Jhanwar-Uniyal M, Sica G, Maira G. Activated ERK1/2 expresssion in glioblastma multiforme and in peritumor tissue. Int J Oncol. 2007; 30:1333-1342

52. Wang H, Wang H, Zhang W, Huang HJ, Liao WS, Fuller GN. Analysis of the activation status of Akt, NFkappaB, and Stat3 in human diffuse gliomas. Lab Invest. 2004; 84:941-951.

53. Faes S, Dormond O. PI3K and AKT: unfaithful partners in cancer. Int J Mol Sci. 2015; 16:21138-21152. 
54. Liu Z, Hou P, Ji M, Guan H, Studeman K, Jensen K, Vasko V, El-Naggar AK, Xing M. Highly prevalent genetic alterations in receptor tyrosine kinases and phosphatidylinositol 3-kinase/akt and mitogen-activated protein kinase pathways in anaplastic and follicular thyroid cancers. J Clin Endocrinol Metab. 2008; 93:3106-3116.

55. Kandil E, Tsumagari K, Ma J, Abd Elmageed ZY, Li X, Slakey D, Mondal D, Abdel-Mageed AB. Synergistic inhibition of thyroid cancer by suppressing MAPK/PI3K/ AKT pathways. J Surg Res. 2013; 184:898-906.

56. Lv B, Yang X, Lv S, Wang L, Fan K, Shi R, Wang F, Song H, Ma X, Tan X, Xu K, Xie J, Wang G, et al. CXCR4 signaling induced epithelial-mesenchymal transition by $\mathrm{PI} 3 \mathrm{~K} / \mathrm{AKT}$ and ERK pathways in glioblastoma. Mol Neurobiol. 2015; 52:1263-1268.

57. Li R, Li Y, Hu X, Lian H, Wang L, Fu H. Transcription factor 3 controls cell proliferation and migration in glioblastoma multiforme cell lines. Biochem Cell Biol. 2016; 94:247-255.
58. Liang J, Slingerland JM. Multiple roles of the PI3K/PKB (Akt) pathway in cell cycle progression. Cell Cycle. 2003; 2:339-345.

59. Lavoie JN, L'Allemain G, Brunet A, Muller R, Pouyssegur J. Cyclin D1 expression is regulated positively by the p42/ p44MAPK and negatively by the p38/HOGMAPK pathway. J Biol Chem. 1996; 271:20608-20616.

60. Pages G, Lenormand P, L'Allemain G, Chambard JC, Meloche S, Pouyssegur J. Mitogen-activated protein kinases p42mapk and p44mapk are required for fibroblast proliferation. Proc Natl Acad Sci U S A. 1993; 90:8319-8323.

61. Gray PA, Fu H, Luo P, Zhao Q, Yu J, Ferrari A, Tenzen T, Yuk DI, Tsung EF, Cai Z, Alberta JA, Cheng LP, Liu Y, et al. Mouse brain organization revealed through direct genome-scale TF expression analysis. Science. 2004; 306:2255-2257. 